\title{
Characterization of non-host resistance in broad bean to the wheat stripe rust pathogen
}

\author{
Yulin Cheng ${ }^{1}$, Hongchang Zhang ${ }^{1,2}$, Juanni Yao ${ }^{1}$, Xiaojie Wang ${ }^{1}$, Jinrong Xu ${ }^{1,3}$, Qingmei Han ${ }^{1}$, Guorong Wei ${ }^{1}$, \\ Lili Huang ${ }^{1}$ and Zhensheng Kang ${ }^{1 *}$
}

\begin{abstract}
Background: Non-host resistance (NHR) confers plant species immunity against the majority of microbial pathogens and represents the most robust and durable form of plant resistance in nature. As one of the main genera of rust fungi with economic and biological importance, Puccinia infects almost all cereals but is unable to cause diseases on legumes. Little is known about the mechanism of this kind of effective defense in legumes to these non-host pathogens.

Results: In this study, the basis of NHR in broad bean (Vicia faba L.) against the wheat stripe rust pathogen, Puccinia striiformis f. sp. tritici (Pst), was characterized. No visible symptoms were observed on broad bean leaves inoculated with Pst. Microscopic observations showed that successful location of stomata and haustoria formation were significantly reduced in Pst infection of broad bean. Attempted infection induced the formation of papillae, cell wall thickening, production of reactive oxygen species, callose deposition and accumulation of phenolic compounds in plant cell walls. The few Pst haustoria that did form in broad bean cells were encased in reactive oxygen and callose materials and those cells elicited cell death. Furthermore, a total of seven defense-related genes were identified and found to be up-regulated during the Pst infection.
\end{abstract}

Conclusions: The results indicate that NHR in broad bean against Pst results from a continuum of layered defenses, including basic incompatibility, structural and chemical strengthening of cell wall, posthaustorial hypersensitive response and induction of several defense-related genes, demonstrating the multi-layered feature of NHR. This work also provides useful information for further determination of resistance mechanisms in broad bean to rust fungi, especially the adapted important broad bean rust pathogen, Uromyces viciae-fabae, because of strong similarity and association between NHR of plants to unadapted pathogens and basal resistance of plants to adapted pathogens.

Keywords: Broad bean, Cell wall, Expression profile, Haustorium, Non-host resistance, Rust fungus

\section{Background}

Non-host resistance (NHR) is resistance exhibited by an entire plant species to all genetic variants of a nonadapted pathogen species (or bacterial pathovar [pv] or fungal forma specialis [f. sp.]) and represents the most robust and durable form of plant resistance in nature [1]. The presence of this defense system explains why plants are immune to the vast majority of potential pathogens and normally healthy. Molecular

\footnotetext{
* Correspondence: kangzs@nwsuaf.edu.cn

${ }^{1}$ State Key Laboratory of Crop Stress Biology for Arid Areas and College of Plant Protection, Northwest A\&F University, Yangling, Shaanxi 712100,

People's Republic of China

Full list of author information is available at the end of the article
}

mechanisms underpinning NHR remain relatively unexplored compared with the well-studied host resistance mediated by the products of plant resistance (R) genes, which establish pathogen race- or plant cultivar-specific resistance [2,3].

NHR against bacteria, fungi and oomycetes can be divided into two types [4]. Type I NHR does not produce visible symptoms whereas type II NHR results in a rapid hypersensitive response with cell death [4]. Type I NHR is much more common than type II NHR, and NHR of plants against the majority of unadapted pathogens belongs to Type I. Plants have evolved sophisticated mechanisms to exclude unadapted pathogens. An obvious initial requirement for plant disease is basic compatibility 
where appropriate physical and chemical signals from the plant are required for inducing cell differentiation and expressing essential pathogenicity genes [5,6]. Presence of preformed plant physical and chemical barriers, including plant cell wall and plant surface antimicrobial enzymes and secondary metabolites, are often considered the first line of defense in plants against a pathogen before penetration [6]. Constitutive barriers are more likely to contribute to NHR to pathogens of other plant families than to pathogens of related plant species [7]. After these constitutive barriers are breached, plants have evolved inducible defense mechanisms against invading pathogens. An example of an inducible structural barrier is the formation of papillae. This local cell wall fortification is formed on the inner side of plant cell walls at the penetration site. All microbes possess a suite of conserved molecules, called MAMPs/PAMPs (microbe/pathogen associated molecular patterns) that can be recognized by plants, often via receptor kinase located in the plant plasma membrane [8]. The plant primary innate immune responses are mediated by transmembrane pattern PAMP-triggered immunity (PTI) that can halt further colonization of the pathogen [9]. However, effector triggered immunity (ETI) is not just confined to adapted pathogen recognition and may also play a role in NHR, particularly against pathogens that colonize plant species closely related to non-host species [10].

Obligate biotrophic pathogens, with a specific lifestyle that keeps plant cells alive and minimizes tissue damage in susceptible hosts, are suitable for NHR studies [11]. Arabidopsis NHR to non-adapted biotrophic powdery mildews is based upon two successive, multicomponent and independently effective defense systems: PEN genemediated pre-invasion resistance and EDS1/PAD4/SAG101controlled post-invasion immunity $[1,12-14]$. Compared to powdery mildew fungi, the understanding of NHR mechanisms to rust fungi has lagged behind. Puccinia and Uromyces represent two large and important genera of rust fungi, which have damaged cereals and legumes, respectively, around the globe throughout history [15]. The emergence of Ug99, a new pathotype of the wheat stem rust pathogen that threatens global wheat production, is a reminder of the need for durable rust resistance in cereals $[16,17]$. Much effort has been taken to study NHR to rust with non-host pathosystems of PucciniaGramineae and Uromyces-dicotyledons at histological and cytological levels, demonstrating that the majority of rust pathogens are arrested immediately after the formation of the first haustorium mother cell (HMC) in most non-host plant species [18-23]. Several recent studies have investigated the interaction of rust pathogens on non-host plants mainly at molecular levels, including growth of $U$. vignae, $P$. triticina, Hemileia vastatrix on Arabidopsis [11,24,25], P. hordei and $U$. fabae on wheat [26,27], P. triticina, P. hordei-murini, $P$. hordei-secalini and P. persistens on barley [28], and $P$. graminis, P. triticina, P. striiformis, P. hordei and Melampsora lini on rice $[5,29]$. These studies demonstrated that NHR to rust fungi is polygenically inherited and is an active response involving salicylic acid (SA) signaling.

Broad bean (Vicia faba L.) is one of the oldest crops cultivated by humans and an important temperate legume crop used as a source of protein in human diets, as fodder and as forage crop for animals, and for available nitrogen in the biosphere [30]. However, broad bean can be seriously damaged by the broad bean rust, caused by U. viciae-fabae. Due to the enormous size (13,000 Mbp) and complexity of the broad bean genome [31], research into the functional genomics and cloning of interesting genes has been hampered.

To date, little is known about the nature of effective defense mechanisms in legumes to pathogens of remotely related plant species, especially wheat rust pathogens with economic and biological importance. In this study, NHR in broad bean to the wheat stripe rust pathogen, $P$. striiformis f. sp. tritici (Pst), was systematically investigated at the histological and molecular levels. The results indicate that NHR in broad bean to Pst results from a continuum of layered defenses and provide useful information for further determination of resistance mechanisms of broad bean to rust fungi.

\section{Results}

\section{Type I NHR to Pst on broad bean}

To determine if different broad bean genotypes show different infection responses to genetically distinct Pst races, two broad bean cultivars, Yuxidabaidou and Linxiadacaidou, were inoculated with three Chinese Pst races CYR23, CYR31 and CYR32, respectively. No visible symptoms were observed 14 days post-inoculation on broad bean leaves (Figure 1), and similar macroscopic responses were obtained from these different combinations. Thus broad bean displayed type I NHR against Pst infection. Additionally, microscopic observations show that no significant differences in fungal growth among these two broad bean cultivars in regard to their interactions with the different Pst races (Table 1).

In regard to economic importance, the pathosystem between Yuxidabaidou that is one main broad bean cultivar grown in Yunnan, China, and CYR32, one of two predominant Pst races in China, can be taken as a representative of the broad bean-Pst non-host interaction and was therefore used for further experiments in the study.

\section{Growth and development of Pst on broad bean}

Approximately, $88 \%$ of Pst urediniospores germinated to produce germ tubes that grew randomly on leaves of the non-host broad bean (Figure 2A, Figure 3A). In a similar 


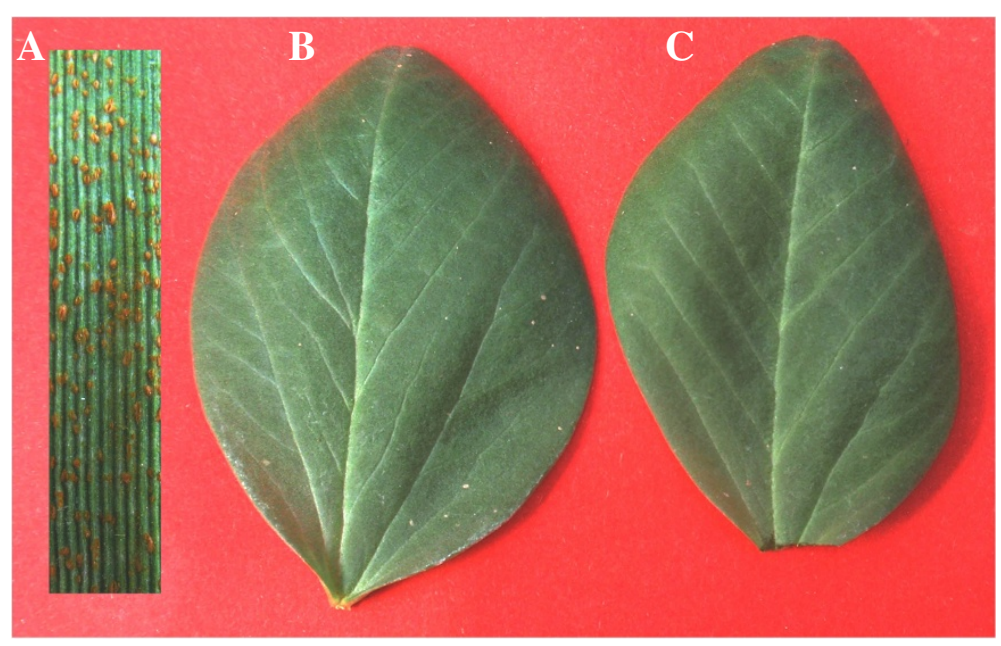

Figure 1 Leaves of wheat and broad bean inoculated with Puccinia striiformis f. sp. tritici were checked 14 days post-inoculation. (A) Massive uredia formed on wheat cultivar Mingxian169. (B) No visible symptoms on broad bean cultivar Yuxidabaidou. (C) A broad bean leaf mock-inoculated with water.

fashion, 91\% of urediniospores produced germ tubes on wheat (Figure $3 \mathrm{~A}$ ). However, only $1.3 \%$ of germ tubes successfully located a broad bean stomate compared to $25 \%$ on wheat (Figure 2B, Figure 3A). Of those germ tubes successfully locating a stomate on broad bean, 96\% subsequently penetrated it and formed an infection hypha (representing an infection unit) compared with $98 \%$ on wheat (Figure 3A). However, of the infection units on broad bean, $28 \%$ contained an aberrant substomatal vesicle (SSV) with an irregular oval shape, which did not coincide with stomata (Figure 2D), 22\% did not have a SSV structure (Figure 2E), and only $50 \%$ contained a normal SSV that formed within the substomatal chamber, which was adjacent to stomata and had a normal oval shape typical of Pst on wheat (Figure 2C). A haustorial mother cell (HMC) was formed at the tip of the infection hypha in close contact with mesophyll cells (Figure 2F). However, only $2 \%$ of infection hyphae formed haustoria within penetrated mesophyll cells (Figure 2F, Figure 3A). In contrast, $88 \%$ of Pst infection

\section{Table 1 No significant differences in fungal growth among two broad bean cultivars in regard to their interactions with three different races of $P$. striiformis f. sp. tritici}

\begin{tabular}{llll}
\hline Broad bean & \multicolumn{3}{l}{ Linear length of infection hyphae $(\boldsymbol{\mu m})$} \\
\cline { 2 - 4 } & CYR23 & CYR31 & CYR32 \\
\hline Yuxidabaidou $^{(1)}$ & $55.47 \pm 1.40$ & $54.73 \pm 1.21$ & $54.95 \pm 1.12$ \\
Linxiadacaidou $^{(2)}$ & $54.97 \pm 0.98$ & $55.07 \pm 0.85$ & $54.29 \pm 1.23$ \\
\hline
\end{tabular}

(1) one main broad bean cultivar grown in Yunnan, China.

(2) one broad bean cultivar grown in Gansu, China.

The linear length of infection hyphae (from the substomatal vesicle to the apex of the longest infection hypha) were measured by microscopy at nine days post-inoculation. Data are mean \pm standard deviation, and there is no statistical difference $(P>0.05)$ compared by Student $t$ tests. hyphae produced a haustorium on wheat (Figure 3A). Therefore, successful location of stomata and development of haustoria were greatly reduced in Pst infection of broad bean.

The linear length of infection hyphae, and numbers of hyphal branching, haustorial mother cells and haustoria per infection unit at a serial time points post-inoculation were also measured, and they were maintained at approximately $55 \mu \mathrm{m}, 1.5,1.0$ and 0.2 , respectively, from 24 hours post-inoculation (hpi) (Figure 3B). Only one or two primary hyphae were produced and the vast majority of the Pst infection hyphae were blocked at haustorium mother cell formation in broad bean leaves compared with extensive colonization and formation of secondary hyphae in wheat leaves at 168 hpi (Figure 2G, H). Thus Pst development was completely arrested from $24 \mathrm{hpi}$.

\section{Histochemical evaluation of broad bean NHR response to Pst}

An active NHR response was shown to be involved in the suppression of Pst growth on broad bean. A domeshaped papilla was formed on the inner side of broad bean cell walls at the penetration site adjacent to the HMC (Figure 4A, D). Thickened cell walls were also present in broad bean mesophyll cells in contact with HMC (Figure 4B). The production of $\mathrm{H}_{2} \mathrm{O}_{2}$ and $\mathrm{O}_{2}{ }^{-}$in broad bean against Pst was analyzed by staining with 3,3'-diaminobenzidine (DAB) and nitroblue tetrazolium (NBT), respectively. Accumulation of $\mathrm{H}_{2} \mathrm{O}_{2}$ was detected at the sites in direct contact with SSV or HMC, and in papilla (Figure 4A, B). In infection units with haustorium formation, $\mathrm{DAB}$ staining was detected at deposits responsible for haustorium encasement (Figure 4C). DAB staining was occasionally observed in the HMC (Figure 4A). 


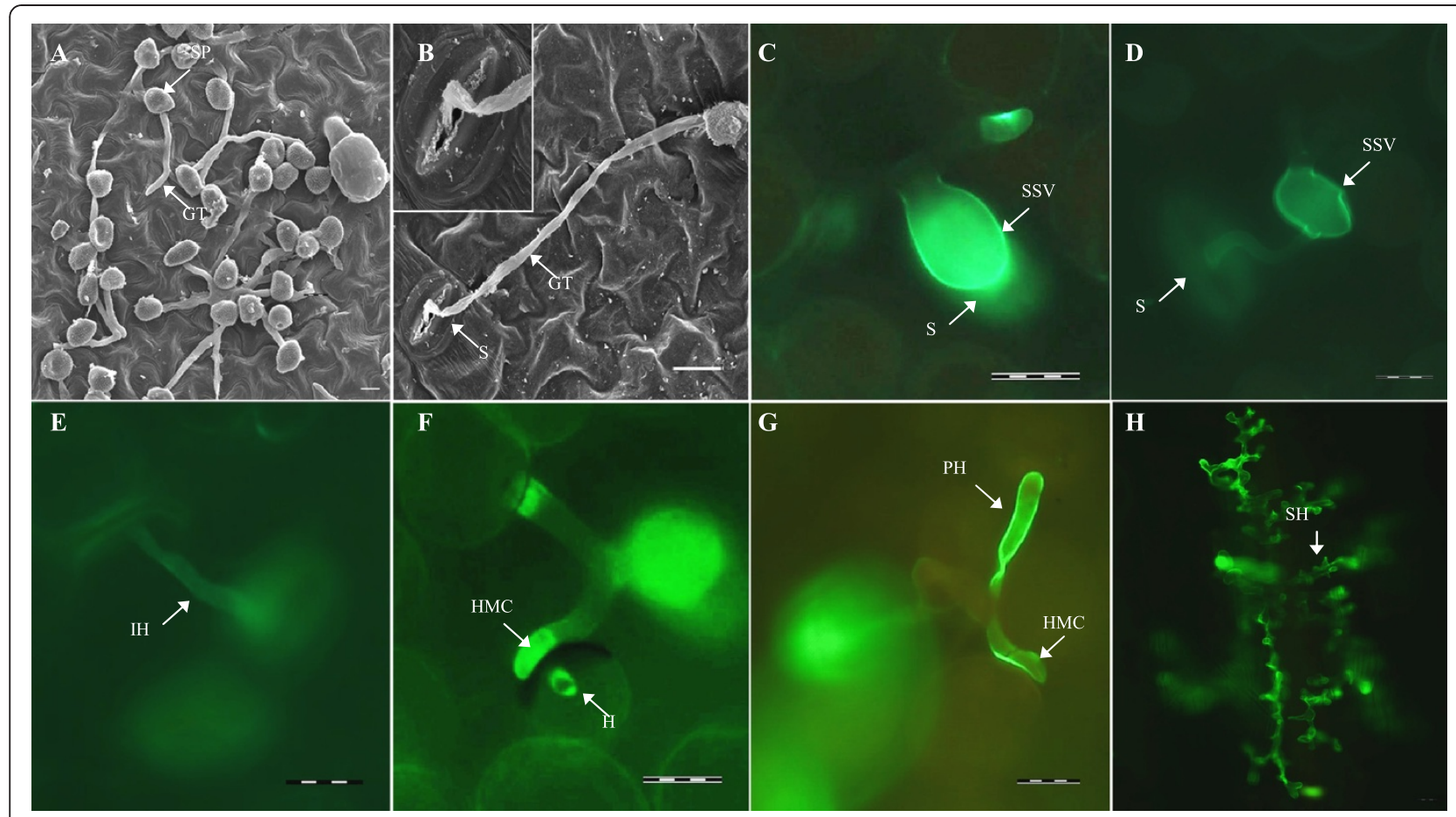

Figure 2 Infection features of $P$. striiformis $\mathbf{f}$. sp. tritici (Pst) on broad bean. (A) Germinated Pst urediniospores (SP) producing germ tubes (GT) growing in random directions at 6 hpi. (B) Germ tube (GT) that has successfully located and entered a stomate (S) at 12 hpi. (C) A normal oval substomatal vesicle (SSV) formed within the substomatal chamber and adjacent to the stomate (S) at 24 hpi. (D) An irregularly shaped SSV formed far from the stomate (S) at 24 hpi. (E) Some infection units did not contain a SSV structure and directly produced infection hyphae (IH) at 24 hpi. (F) A Pst haustorium (H) within a mesophyll cell after penetration by a haustorial mother cell (HMC) at 24 hpi. (G, H) Broad bean and wheat inoculated with Pst, respectively, at $168 \mathrm{hpi}$. Only one or two primary hyphae (PH) were produced and the vast majority of the Pst infection hyphae were blocked at HMC formation in broad bean leaves compared with extensive colonization and formation of secondary hyphae $(\mathrm{SH})$ in wheat leaves. Leaves were examined under a scanning electron microscope (A, B) and under an epifluorescence microscope after staining with Calcofluor (C-E), or with WGA-alexa staining (F-H). Bar $=20 \mu \mathrm{m}$.

The percentage of infection units with DAB staining increased rapidly from 12 to $24 \mathrm{hpi}$ and then gradually declined (Figure 5). NBT staining was not detected in plant cells of any sample (Figure 5).

Aniline blue staining indicated that callose deposition was associated with the rust infection units and staining at 24 hpi showed the same distribution as $\mathrm{H}_{2} \mathrm{O}_{2}$ in the plant cell walls at the sites in direct contact with SSV or HMC, in papilla, and at encasement of haustoria (Figure 4D-F). Therefore, attempted Pst infection of broad bean resulted in rapid production and accumulation of $\mathrm{H}_{2} \mathrm{O}_{2}$ (but not $\mathrm{O}_{2}{ }^{-}$) and callose deposition, presumably related to the generation of subcellular, localized physical barriers.

The cell walls of mesophyll cells in contact with infection hyphae and neighboring mesophyll cells showed intense bright fluorescence (Figure 4G, H), which is likely related to the accumulation of antimicrobial phenolic compounds. Hypersensitive response (HR) with cell death occurred in infection units with haustoria formation as evidenced by plant cell autofluorescence at $24 \mathrm{hpi}$ (Figure 4I). Penetrated mesophyll cells began to collapse from 48 hpi (Figure 4J).
Collectively, attempted infection induced the formation of papillae, cell wall thickening, production of reactive oxygen species, callose deposition, and accumulation of phenolic compounds in non-host plant cells. The few haustoria that were formed by Pst in broad bean cells were encased in reactive oxygen and callose materials and elicited a posthaustorial hypersensitive response.

\section{Quantitative real-time PCR (qRT-PCR) of seven candidate defense-related genes}

Seven defense-related genes that may be involved in basal resistance, oxidative stress responses and callose formation were selected for qRT-PCR assays. They are putative pathogenesis-related gene 1 (PR1), pathogenesis-related gene 2 (PR2), pathogenesis-related gene 5 (PR5), pathogenesis-related gene 10 (PR10), superoxide dismutase $(S O D)$, catalase $(C A T)$, glucan synthaselike 5 (GSL5). These genes on broad bean were identified using homologous sequences deposited in GenBank of species closely related to broad bean (Table 2) for designing a set of primers (see Additional file 1). These genes 

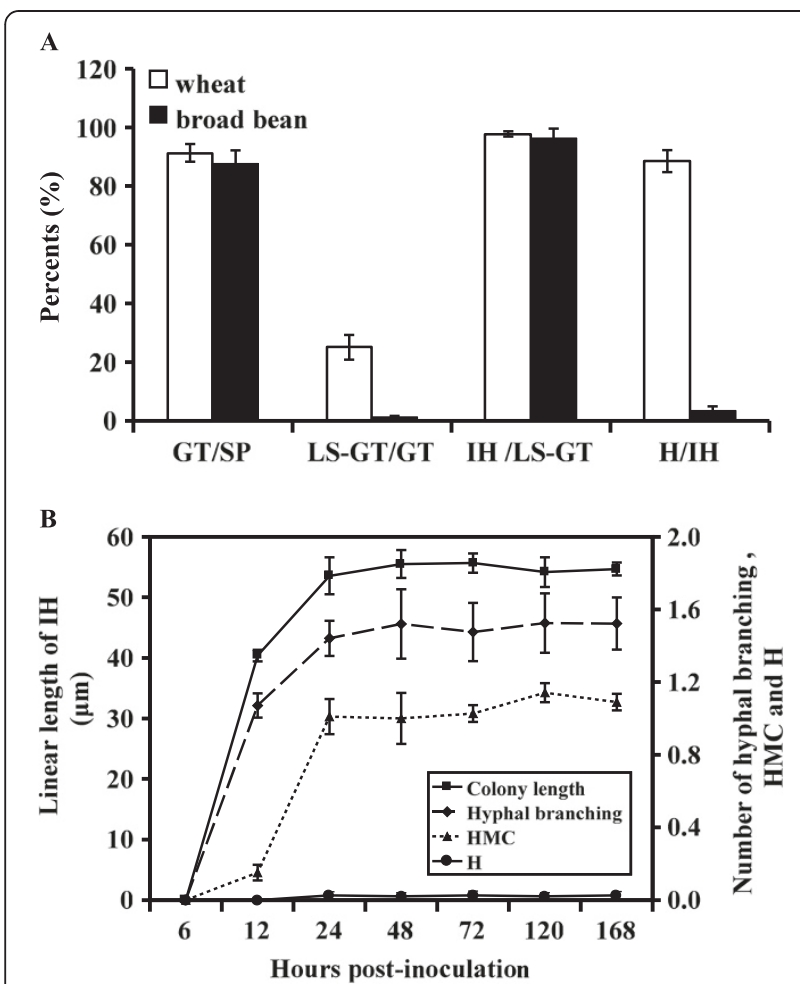

Figure 3 Limited growth and development of $P$. striiformis $\mathbf{f}$. sp. tritici (Pst). (A) Frequencies of each stage of Pst development on broad bean compared with wheat at $48 \mathrm{hpi}$. SP, urediniospore; GT, germ tube; LS-GT, germ tube locating a stomate; $\mathrm{HH}_{\text {, infection hypha; }}$ $\mathrm{H}$, haustorium. GT/SP, percentage of the urediniospores producing germ tubes (GT) among total urediniospores (SP); LS-GT/GT, percentage of germ tubes locating stomata (LS-GT) among all germ tubes (GT); IH/LS-GT, percentage of germ tubes locating stomata (LS-GT), successfully penetrating them and forming infection hypha $(\mathrm{IH}) ; \mathrm{H} / \mathrm{IH}$, percentage of haustoria $(H)$ formation among all infection hyphae (IH). (B) Linear length of infection hyphae (syn. colony length) (from the substomatal vesicle to the apex of the longest infection hypha), and numbers of hyphal branches, haustorium mother cells $(H M C)$ and haustoria $(H)$ formed per infection units measured at continuous time points after inoculation. Linear length of infection hyphae is the left Y-axis; numbers of hyphal branching, haustorium mother cells (HMC) and haustoria $(\mathrm{H})$ are indicated by the right $Y$-axis. Mean values from three independent replications. Vertical bars represent the standard deviations.

[GenBank: JQ043345-JQ043351] showed 75-97\% identities to those used to design primers, and were used for assessments of expression by qRT-PCR, although their full lengths were not available.

A set of primers based on the cloned sequences of the seven defense-related genes were designed (see Additional file 2), and qRT-PCR was performed to test their expression profiles during Pst infection across a series of time points post-inoculation on broad bean. As shown in Figure 6, accumulations of VfPR1, VfPR2, VfPR5, and VfPR10 transcripts were up-regulated as early as $12 \mathrm{hpi}$, peaked at $24 \mathrm{hpi}$, and declined to original expression levels except for VfPR2 that remained at a high level at $72 \mathrm{hpi}$
(Figure 6A-6D). Accumulations of transcripts of VFSOD and $V f C A T$, which are involved in oxidative stress peaked at $12 \mathrm{hpi}$, but the induction of $V f C A T$ expression was as early as $6 \mathrm{hpi}$ (Figure 6E, F). Transcription of VfGSL5, a callose formation gene, was up-regulated from 12 hpi to 24 hpi and then sharply declined (Figure 6G). These results indicated that Pst infection triggered the induction of a set of defense-related genes in broad bean peaking at 12 and 24 hpi.

\section{Discussion}

Non-host resistance (NHR) with obvious durability has been studied as a source of resistance traits that might help in improving crop performance in the glasshouse and the field $[6,32]$. In the present study, a continuum of layered defenses led to NHR in broad bean. No visible symptoms were observed on broad bean leaves inoculated with Pst, indicating type I NHR. However, a hypersensitive response (HR) with cell death in infection units with haustorium formation was also observed in broad bean leaves by microscopic examination. Similar results were observed in the interactions between other rust fungi and non-host plants [20,22,23]. In NHR analysis of Arabidopsis to Phytophthora infestans infection, penetrated epidermal cells also displayed a rapid hypersensitive response, although no symptoms could be detected [33]. Therefore, HR that cannot be detected on visual symptoms, may be observed at the single cell level in Type I NHR, which is probably related to low infection probability and an extremely rapid HR on non-host plants.

On non-host broad bean leaves, urediniospores of Pst germinated at a similar frequency to those on wheat leaves. However, the germ tubes grew randomly without directional growth on broad bean leaves. There was an approximate twenty fold difference in successful location of stomata on broad bean compared to wheat. It appeared that urediniospores germinated well but had difficulty in locating and recognizing stomata on nonhost plants [20]. This difference may be due to inappropriate thigmotrophic or biochemical signals arising from the broad bean leaves. This basic incompatibility therefore reduced Pst infection efficiency on broad bean by reducing the probability of germ tubes locating stomata ( $25 \%$ on wheat compared with $1.3 \%$ on broad bean). This was somewhat comparable to $85 \%$ and $12 \%$ reported for $P$. triticina $(P t)$ on its wheat host compared to a non-host, Arabidopsis thaliana [24]. Moreover, in a graminaceous comparison similar inefficiencies by Pst, Pt, and P. graminis f. sp tritici $(P g t)$ in locating stomata in rice compared to wheat were observed (unpublished results). Again Pst was more inefficient than the other two species. The major difference in the infection process between Pst and other rust fungi is that it does not form obvious appressoria, and germ tubes directly penetrate the stomata. This 

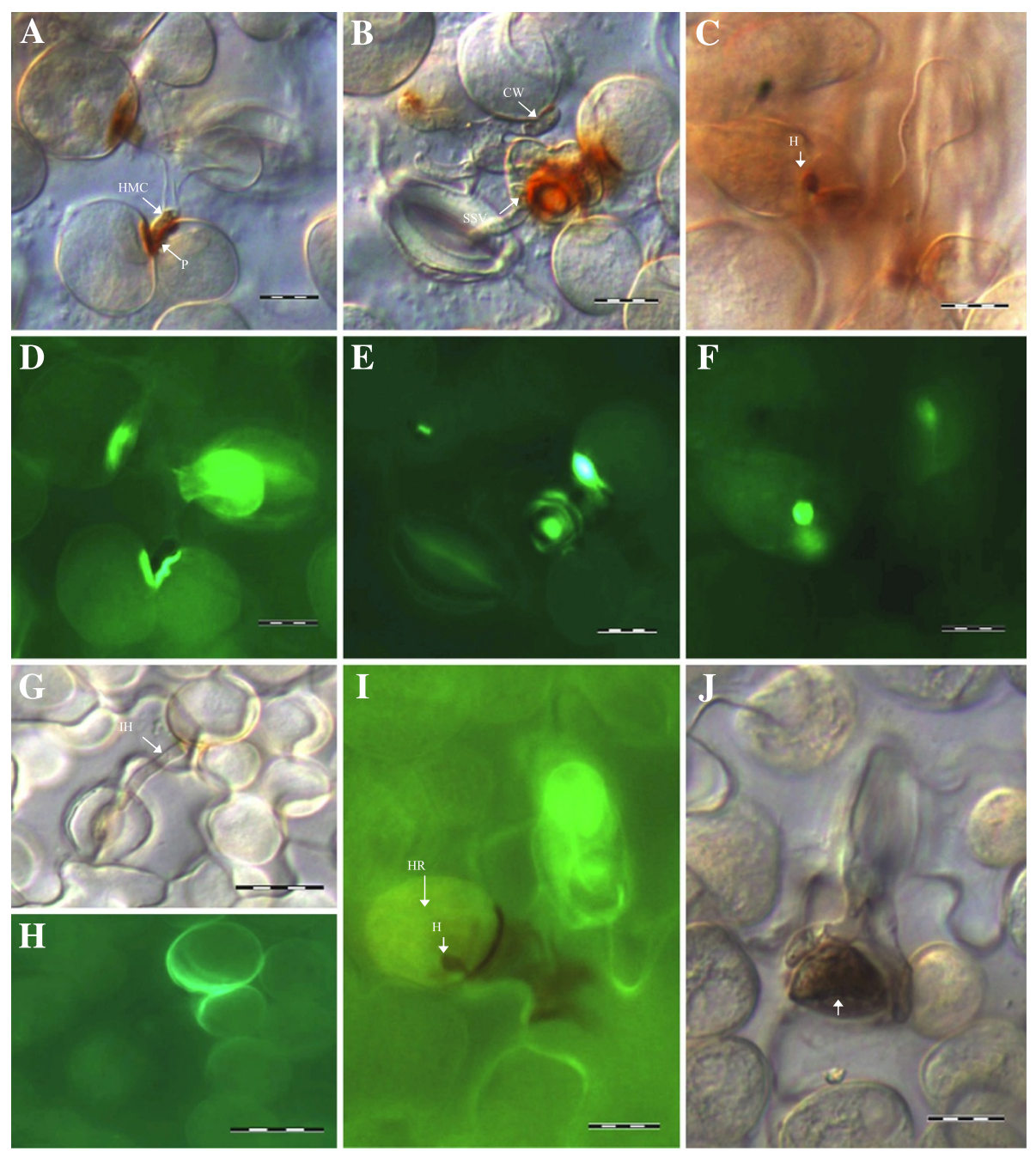

Figure 4 Broad bean responses to attempted $P$. striiformis f. sp. tritici (Pst) infection. (A-C) Inoculated broad bean leaves were stained with 3,3-diaminobenzidine (DAB) to detect production of $\mathrm{H}_{2} \mathrm{O}_{2}$ (reddish brown) at 24 hpi. A dome-shaped papilla (P) (A) and thickened cell walls (CW) (B) were formed in the broad bean cell walls in contact with the fungal haustorial mother cells (HMC). DAB staining was visible in the mesophyll cell wall adjacent to a HMC (A), the mesophyll and epidermal cell in contact with a substomatal vesicle (SSV) (B), the papilla (A), the encasement surrounding the haustorium $(\mathrm{H})(\mathbf{C})$, and an $\mathrm{HMC}$ of Pst (A). (D-F) Callose deposition (intensive green fluorescent) coinciding with $\mathrm{H}_{2} \mathrm{O}_{2}$ distribution (A-C) was detected by aniline blue staining at $24 \mathrm{hpi}$. (G) A mesophyll cell in contanct with an infection hypha (IH) at 24 hpi. (H) Bright fluorescence was observed in the cell walls of the mesophyll cell and a neighboring mesophyll cell at the same infection unit shown in (G). (I) In some infection units with formation of haustoria (H), plant cell autofluorescence, indicative of HR was detected at $24 \mathrm{hpi}$. (J) Collapsed mesophyll cell (arrow) at 72 hpi. Bar $=20 \mu \mathrm{m}$.

possibly increases the difficulty in locating and recognizing stomata.

Among Pst infection units, some contained an aberrant substomatal vesicle (SSV), and some did not. This difference may be related to different leaf structures between legume and cereal plants, especially the structure and size of the substomatal chambers. The vast majority of Pst infection hyphae were blocked at haustorium mother cell formation, which is likely due to plant resistance responses, including papilla formation and cell wall thickening. In other incompatible leguminous-rust or powdery mildew interactions, papilla were frequently observed on plant cell walls [34-36]. It is possible that papilla formation is one of general defense responses effective against biotrophic pathogens in legumes. Attempted Pst infection also induced the production of reactive oxygen species, callose deposition, and the accumulation of phenolic compounds in plant cells. We also observed that the haustoria were encased in reactive oxygen and callose materials and elicited plant cell 


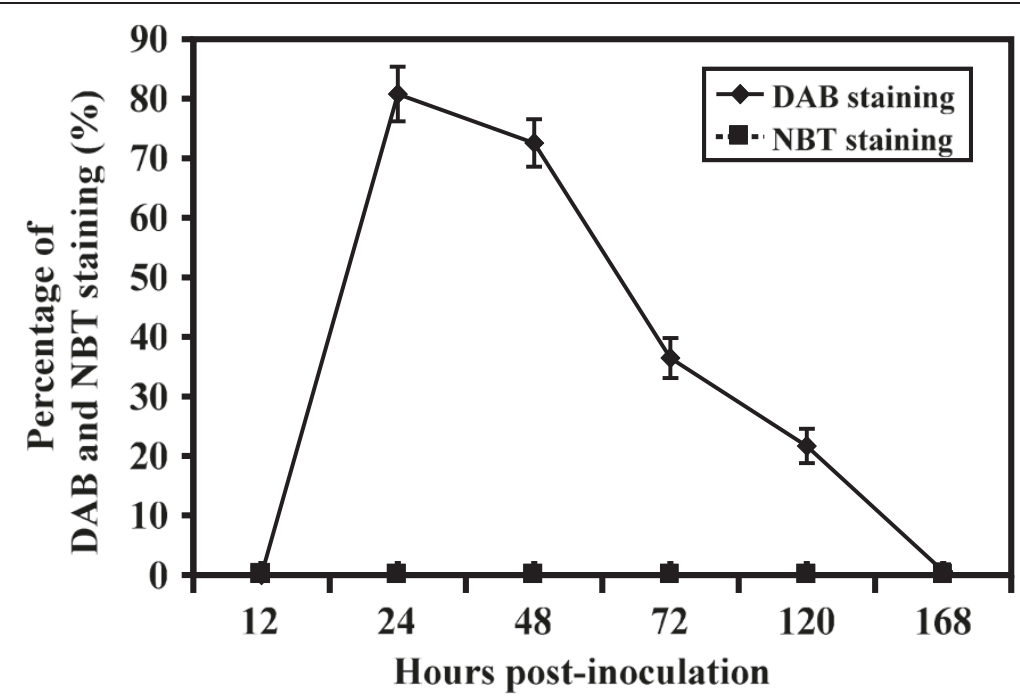

Figure 5 Percentage of infection units exhibiting $\mathrm{H}_{2} \mathrm{O}_{2}$ (DAB staining) and $\mathrm{O}_{2}^{-}$(NBT staining) accumulation on broad bean after inoculation with $\boldsymbol{P}$. striiformis $\mathbf{f}$. sp. tritici. Each point represents at least 50 infection units from eight to ten inoculated broad bean leaves. These experiments were repeated three times with similar results. Bars represent standard deviation.

death. Hydrogen peroxide $\left(\mathrm{H}_{2} \mathrm{O}_{2}\right)$ and callose deposition with the same distribution were detected at $24 \mathrm{hpi}$, coinciding with the fact that the activation of CAT, SOD and GSL5 genes at 12 to $24 \mathrm{hpi}$. The balance between SOD and $A P X$ or $C A T$ activities in cells is crucial for determining a steady-state balance of superoxide radicals and hydrogen peroxide [37]. U. fabae infection also triggered the induction $S O D$ and CAT genes in wheat [26]. GSL5 encodes a glucan synthase involved in papillary callose formation and callose encasement of haustorial complexes in response to the powdery mildew pathogen [38]. GSL5 gene was also activated in Arabidopsis thaliana against the coffee leaf rust fungus Hemileia vastatrix [25]. GSL5 may therefore be also involved in papillary callose formation and callose encasement of haustorial complexes in response to the rust fungi. $\mathrm{H}_{2} \mathrm{O}_{2}$ can facilitate crosslinking of cell walls [39], and callose ( $\beta$-1,3-glucan) deposition may reinforce cell walls at contact sites with fungal structures. Phenolic compounds, as one of chemical barrier in inducible defense mechanisms in Type I NHR [4], have been reported to have antimicrobial activity [40].

Therefore, prehaustorial NHR with basic incompatibility and structural and chemical strengthening of cell walls against the majority of penetrating fungal units, and posthaustorial NHR with a hypersensitive response against the few successful penetrations, collectively contribute to the NHR of broad bean to Pst. These features also demonstrate the multi-layered feature of NHR.

Table 2 Descriptions of candidate defense-related genes

\begin{tabular}{|c|c|c|c|c|c|}
\hline Name & Annotation & Related species & Accession number ${ }^{(1)}$ & Arabidopsis homolog locus ${ }^{(2)}$ & BLASTX score/E Value ${ }^{(3)}$ \\
\hline & Basal resistance & & & & \\
\hline PR1 & Pathogenesis-related gene 1 & Pisum sativum & CAE51954.1 & AT2G14610.1 & $200 / 4 e-52$ \\
\hline PR2 & Beta-1, 3-endoglucanase & Pisum sativum & AAB24398.1 & AT3G57260.1 & $242 / 5 e-80$ \\
\hline PR5 & Thaumatin-like protein & Medicago truncatula & TC100682 (4) & - & - \\
\hline \multirow[t]{2}{*}{ PR10 } & Pathogenesis-related gene 10 & Pisum sativum & U31669.1 & $-^{(5)}$ & - \\
\hline & Oxidative stress responses & & & & \\
\hline SOD & Superoxide dismutase & Pisum sativum & CAA39819.1 & AT5G18100.1 & $181 / 5 e-61$ \\
\hline \multirow[t]{2}{*}{ CAT } & Catalase & Pisum sativum & BAH37035.1 & AT1G20620.1 & $828 / 0$ \\
\hline & Papillary callose formation & & & & \\
\hline GSL5 & Glucan synthase-Like 5 & Medicago truncatula & ABN09771.1 & AT4G03550.1 & $1110 / 0$ \\
\hline
\end{tabular}

(1) GenBank accession number: www. ncbi.nlm.nih.gov.

(2) Closest Arabidopsis homolog identified using TAIR BLAST.

(3) score/E value between Arabidopsis homolog locus and legume species by BLASTX.

${ }^{(4)}$ Medicago truncatula Gene Index tentative consensus (TC) numbers for cDNAs on the microarray (http://www.tigr.org/tigr-scripts/tgi/T_index.cgi? species=medicago).

(5) No sequence of PR10 in Arabidopsis using TAIR BLAST. 

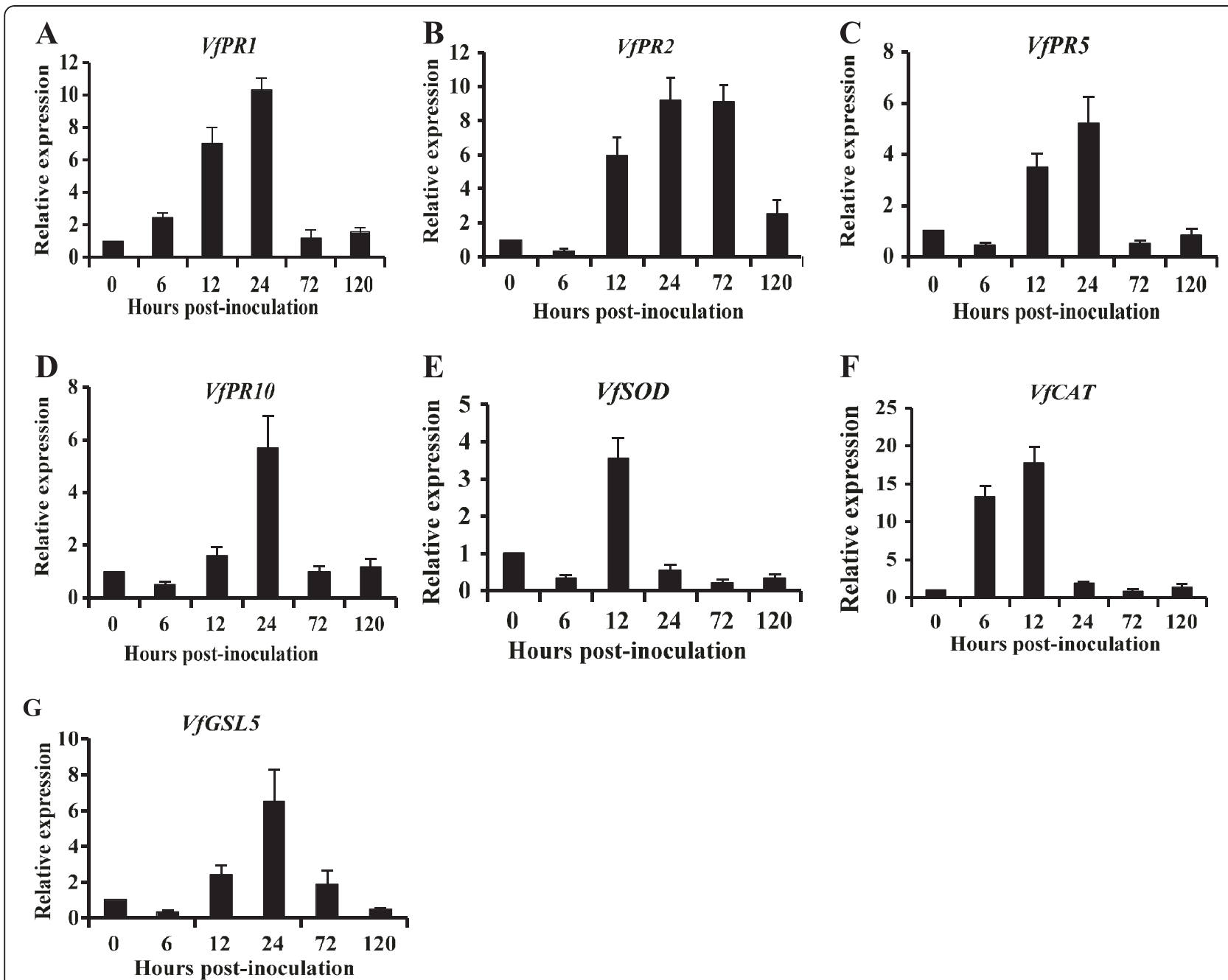

Figure 6 Relative transcript levels of seven defense-related genes assayed by qRT-PCR. Relative gene expression was quantified by the comparative $2^{-\nabla \nabla C T}$ method. The mean expression value was calculated from three independent replications. Vertical bars represent the standard deviations.

Pathogen-related proteins encompass several different groups of structurally and functionally unrelated proteins with antimicrobial activities [41]. Four PR genes observed were up-regulated in response to Pst infection in broad bean leaves. The expression of all four PR genes is SA responsive $[42,43]$. PR1 is widely thought to be a molecular marker for the SA-dependent resistance signaling pathway $[41,44]$. Thus, SA-mediated resistance pathway is involved in the non-host broad bean-Pst interaction. PR2 protein, which has $\beta$-1,3-glucanase activity, can degrade fungal cell walls, together with $P R 3$ protein, which has chitinolytic activity, cause the lysis of fungal cell walls [45]. We failed to isolate the PR3 gene from broad bean. Nevertheless, transcription of the PR2 gene occurred at a high level from 12 to $72 \mathrm{hpi}$, likely playing a role in inhibiting the growth of Pst. Plasma membrane- permeabilizing ability proper to PR5 contributes to plasmolysis and damage of fungal and bacterial pathogens, inhibiting their growth and development [46]. PR10 involves in plant defense responses and has antimicrobial activity and in vitro ribonuclease activity $[47,48]$.

In the non-host interaction between broad bean and Pst, transcript accumulations of PR genes and the GSL5 gene involved in callose formation were up-regulated at 12-24 hpi with a peak at $24 \mathrm{hpi}$, whereas transcript accumulations of $S O D$ and $C A T$ involved in oxidative stress responses were up-regulated as early as 6-12 hpi with peaks at $12 \mathrm{hpi}$. The accumulation of hydrogen peroxide $\left(\mathrm{H}_{2} \mathrm{O}_{2}\right)$ can lead to SA synthesis [49], and elevated levels of SA along with $\mathrm{H}_{2} \mathrm{O}_{2}$ can activate local PR gene expression [50]. $\mathrm{H}_{2} \mathrm{O}_{2}$ produced during early plant-pathogen interactions also contributes to cell wall strengthening processes, such as the formation of papilla where callose is abundantly deposited [51]. Thus, $\mathrm{H}_{2} \mathrm{O}_{2}$ as a singal substance may activate the expression of PR genes 
and contribute to callose formation in the non-host interaction. This could explain the earlier induction of $S O D$ and CAT compared to PR genes and GSL5.

Although limited by current genomic and transcriptomic data for broad bean, several defense-related genes were successfully identified using the homology cloning approach. We failed to get specific amplification products when using primers designed on the basis of soybean (Glycine max) gene sequences. In contrast, positive amplification was obtained using primers designed from pea (Pisum sativum) sequences. Similar results were obtained with amplification of other genes [52]. Because of huge genome in broad bean, it was necessary to rely on synteny with related species in order to identify interesting genes [52]. This approach allowed us to identify candidate genes responsible for agronomically important traits in broad bean.

\section{Conclusions}

In this study, we characterized the basis of NHR in broad bean against Pst, a pathogen of remotely related plant species, at the histological and molecular levels. Our results indicate that the NHR involves a continuum of layered defense processes, including basic incompatibility, structural and chemical strengthening of the cell wall, posthaustorial hypersensitive response and induction of several defense-related genes, demonstrating the multi-levels feature of NHR. NHR of plants to unadapted pathogens exhibits strong similarity and association with basal resistance of plants to adapted pathogens [7]. Therefore, this study of NHR to Pst in broad bean provides useful information for further determination of resistance mechanisms in broad bean to rust fungi, especially the adapted important broad bean rust pathogen, $U$. viciae-fabae. Meanwhile, we confirm that $\mathrm{HR}$ can be observed at the single cell level, although there are no visible symptoms in Type I NHR.

\section{Methods}

\section{Plants, pathogens and inoculation}

Two broad bean cultivars used in this study are Yuxidabaidou and Linxiadacaidou. Yuxidabaidou is one main cultivar grown in Yunnan (the main growing area for broad bean in China) and Linxiadacaidou is one cultivar grown in Gansu, China. Wheat cultivar Mingxian169 and Pst races CYR23, CYR31, CYR32 used in this study were obtained from the College of Plant Protection. Plants were grown in a soil mixture in $10 \mathrm{~cm}$ diameter pots in a growth chamber at $20^{\circ} \mathrm{C}$ with $60 \%$ relative humidity and a $16 \mathrm{~h}$ photoperiod $\left(60 \mu \mathrm{mol} \mathrm{m}{ }^{-2} \mathrm{~s}^{-1}\right.$ photon flux density). Broad bean plants at the 5-6 leaf stage and wheat at the 1-2 leaf stage were used for inoculation. Pst was maintained and propagated on the susceptible wheat cultivar Mingxian 169.
For inoculation, fresh urediniospore suspensions $(50 \mathrm{mg}$ $\mathrm{ml}^{-1}$ ) were applied with a fine paintbrush onto the adaxial surfaces of leaves of broad bean and wheat plants. Parallel mock inoculations were performed with tap water. Inoculated seedlings were put into a dark humidity chamber for $24 \mathrm{~h}$ at $16^{\circ} \mathrm{C}$ and then moved to the growth chamber. Leaf samples were collected at specific time points for various analyses and disease symptoms were recorded $14 \mathrm{dpi}$.

\section{Light microscopy}

Infected broad bean and wheat leaf pieces of $2-3 \mathrm{~cm}^{2}$ were harvested at set time points, fixed and decolorized in ethanol/trichloromethane $(3: 1, \mathrm{v} / \mathrm{v})$ containing $0.15 \%$ $(\mathrm{w} / \mathrm{v})$ trichloroacetic acid for 3-5 days and then cleared in saturated chloral hydrate until leaf tissues were translucent. For microscopic observations, leaf segments were stored in 50\% glycerol and examined under differential interference contrast (DIC) optics.

To visualise the pathogen structures, the leaves were stained with Calcofluor (Sigma-Aldrich, St. Louis, MO, USA) [53]. For better visualisation of internal infection structures, the staining procedure for wheat germ agglutinin (WGA) conjugated to the fluorophore alexa 488 (Invitrogen, USA) was also used as described previously [29]. All fluorescence stained tissues were examined under a fluorescence microscope.

For each broad bean leaf sample, at least 50 infection units from 8-10 leaf segments were examined for recording linear length of infection hyphae, and numbers of hyphal branching, haustorial mother cells and haustoria per infection unit. The linear length of infection hyphae was measured from the substomatal vesicle to the apex of the longest infection hypha. All microscopic examinations were done with an Olympus BX-51 microscope (Olympus Corporation, Japan).

\section{Scanning electron microscopy}

Leaf tissues were cut into small pieces $(0.5-1 \mathrm{~cm})$, fixed in $4 \%(\mathrm{v} / \mathrm{v})$ glutaraldehyde in phosphate buffer $(0.1 \mathrm{M}$, $\mathrm{pH}$ 6.8) for $8-10 \mathrm{~h}$ at $4^{\circ} \mathrm{C}$, then rinsed with the same buffer for 1-2 h. After dehydration in a graded ethanol series, the samples were critical-point dried, coated with gold in a sputter coater, and examined under a JEOL JSM-6360 LV scanning electron microscope at $15 \mathrm{kV}$.

\section{Histochemical analysis}

$\mathrm{H}_{2} \mathrm{O}_{2}$ and $\mathrm{O}_{2}^{-}$production was detected in plant tissue by staining with 3-3/ diaminobe-nzidine (DAB) (Amresco, Solon, OH, USA) and nitroblue tetrazolium (NBT) (Amresco, Solon, OH, USA), respectively. Specimen preparation and microscopic observations were performed following procedures previously described $[54,55]$.

Callose deposition was visualised under UV light after modified aniline blue staining as described previously [56]. After DAB uptake, leaf segments were fixed and cleared, 
and washed twice with 50\% (v/v) ethanol for $15 \mathrm{~min}$, rinsed with water, then incubated in $0.067 \mathrm{M} \mathrm{K}_{2} \mathrm{HPO}_{4}$ (pH 9.0) for $30 \mathrm{~min}$, and stained with $0.05 \%(\mathrm{w} / \mathrm{v})$ aniline blue overnight. Specimens were examined with an Olympus BX-51 microscope (Olympus Corporation). Autofluorescence of attacked mesophyll cells was observed as necrotic cell death by an epifluorescence microscopy (excitation filter, $485 \mathrm{~nm}$; dichromic mirror, $510 \mathrm{~nm}$; and barrier filter, $520 \mathrm{~nm})$.

\section{RNA extraction and CDNA synthesis}

Total RNA of broad bean leaves was extracted using the TrizolTM Reagent (Invitrogen, Carlsbad, CA, U.S.A.). DNaseI treatment was applied to remove genomic DNA. The integrity of total RNA was checked by formamide denaturing gel electrophoresis, and the concentration was determined with a NanoDropTM 1000 spectrophotometer (Thermo Fisher Scientific, U.S.A.). About 3 ug total RNA was used to generate the first-strand cDNA using the Promega RT-PCR system (Promega, Madison, WI, U.S.A.) with the Oligo (dT)18 primer and cDNA constructions were carried out according to the manufacturer's instructions.

\section{Identification of defense-related genes}

Each gene were firsted identified from Arabidopsis and used in BLASTX analysis to search for corresponding orthologous sequences in legume species closely related to broad bean (Table 2). Then, gene-specific primers at conservative positions were designed with Primer Premier 5.0 and used in RT-PCR for cloning the targeted broad bean genes (see Additional file 1). PCR products were cloned and sequenced, followed by analysis using the BLASTX algorithm to confirm the gene specificity.

\section{Quantitative real-time PCR analysis}

Gene expression patterns of seven genes were analyzed by qRT-PCR analysis. Based on the broad bean genes identified, primers were designed (Additional file 2). Eukaryotic elongation factor 1-alpha (ELF1A) [GenBank: O24534] was used as an internal reference for the qRT-PCR analysis [52]. Quantification of gene expression was performed using a 7500 Real-Time PCR System (Applied Biosystems, Foster City, CA, USA). To avoid variations caused by experimental conditions, the expression level of each gene in the mock-inoculated control was subtracted from that in broad bean leaves inoculated with Pst. Dissociation curves were generated for each reaction to ensure specific amplification. Threshold values (CT) generated from the ABI PRISM 7500 Software Tool (Applied Biosystems, Foster City, CA, USA) were used to quantify relative gene expression using the comparative $2^{-\nabla \nabla \mathrm{CT}}$ method [57].

\section{Statistical analyses}

All experiments were repeated three times with similar results. At least 50 infection sites from eight to ten leaf sections per time point were examined in histopathological and histochemical sections. Means and standard deviation were estimated from three independent experiments using SAS software.

\section{Additional files}

Additional file 1: Primers used for cloning the seven defense-related genes.

Additional file 2: Primers used in quantitative real-time PCR.

\section{Abbreviations}

DAB: 3,3-diaminobenzidine; DIC: Differential interference contrast; ETI: Effector triggered immunity; HMC: Haustorial mother cell; hpi: Hours post-inoculation; HR: Hypersensitive response; MAMPS or PAMPs: Microbial- or pathogenassociated molecular patterns; NBT: Nitroblue tetrazolium; NHR: Non-host resistance; Pst: Puccinia striiformis f. sp. tritici; PTI: PAMP-triggered immunity; qRT-PCR: Quantitative realtime-PCR; SA: Salicylic acid; SSV: Substomatal vesicle.

\section{Competing interests}

The authors declare that they have no competing interests.

\section{Authors' contributions}

YLC designed experiments, performed the experiments and wrote manuscript. HCZ designed experiments and provided assistance in some experiments. JNY performed cytological experiments and provided assistance in some experiments. XJW and JRX provided advice for experiments and revised the manuscript. GRW prepared samples and collected data. LLH coordinated the experiments and analyzed the data. ZSK conceived the project, helped design the experiments and wrote the manuscript. All authors read and approved the final manuscript.

\section{Acknowledgments}

This study was financially supported by Modern Agro-industry Technology Research System in China, the National Natural Science Foundation of China (No. 30930064), the Specialized Project of Transgenic Crops of Ministry of Science and Technology of China (2009ZX08009-051B) and the 111 Project from the Ministry of Education of China (B07049).

\section{Author details}

${ }^{1}$ State Key Laboratory of Crop Stress Biology for Arid Areas and College of Plant Protection, Northwest A\&F University, Yangling, Shaanxi 712100, People's Republic of China. ${ }^{2}$ College of Life Sciences, Northwest A\&F University, Yangling, Shaanxi 712100, People's Republic of China. ${ }^{3}$ Department of Botany and Plant Pathology, Purdue University, West Lafayette, IN 47907, USA.

Received: 2 February 2012 Accepted: 7 June 2012 Published: 21 June 2012

\section{References}

1. Lipka U, Fuchs R, Kuhns C, Petutschnig E, Lipka V: Live and let dieArabidopsis nonhost resistance to powdery mildews. Eur J Cell Biol 2010, 89:194-199.

2. Dangl JL, Jones JDG: Plant pathogens and integrated defence responses to infection. Nature 2001, 411:826-833.

3. Schulze-Lefert P, Bieri S: Recognition at a distance. Science 2005, 308:506-508.

4. Mysore KS, Ryu CM: Nonhost resistance: how much do we know? Trends Plant Sci 2004, 9:97-104.

5. Ayliffe $M$, Jin $Y$, Kang Z, Persson M, Steffenson B, Wang S, Leung $H$ : Determining the basis of nonhost resistance in rice to cereal rusts. Euphytica 2011, 179:33-40. 
6. Thordal-Christensen $\mathrm{H}$ : Fresh insights into processes of nonhost resistance. Current Opinion in Plant Biology 2003, 6:351-357.

7. Niks RE, Marcel TC: Nonhost and basal resistance: how to explain specificity? New Phytol 2009, 182:817-828.

8. Zipfel C: Pattern-recognition receptors in plant innate immunity. Curr Opin Immunol 2008, 20:10-16.

9. Jones JDG, Dangl JL: The plant immune system. Nature 2006, 444:323-329.

10. Schulze-Lefert P, Panstruga R: A molecular evolutionary concept connecting nonhost resistance, pathogen host range, and pathogen speciation. Trends Plant Sci 2011, 16:117-125.

11. Mellersh DG, Heath MC: An investigation into the involvement of defense signaling pathways in components of the nonhost resistance of Arabidopsis thaliana to rust fungi also reveals a model system for studying rust fungal compatibility. Molecular Plant-Microbe Interactions 2003, 16:398-404.

12. Collins NC, Thordal-Christensen H, Lipka V, Bau S, Kombrink E, Qiu JL, Hückelhoven R, Stein M, Freialdenhoven A, Somerville SC: SNARE-proteinmediated disease resistance at the plant cell wall. Nature 2003, 425:973-977.

13. Lipka V, Dittgen J, Bednarek P, Bhat R, Wiermer M, Stein M, Landtag J, Brandt W, Rosahl S, Scheel D: Pre- and postinvasion defenses both contribute to nonhost resistance in Arabidopsis. Science 2005, 310:1180-1183.

14. Stein M, Dittgen J, Sánchez-Rodríguez C, Hou BH, Molina A, Schulze-Lefert P, Lipka V, Somerville S: Arabidopsis PEN3/PDR8, an ATP binding cassette transporter, contributes to nonhost resistance to inappropriate pathogens that enter by direct penetration. The Plant Cell 2006, 18:731-746.

15. Voegele RT: Uromyces fabae: development, metabolism, and interactions with its host Vicia faba. FEMS Microbiol Lett 2006, 259:165-173.

16. Ayliffe $M$, Singh $R$, Lagudah E: Durable resistance to wheat stem rust needed. Current Opinion in Plant Biology 2008, 11:187-192.

17. Stokstad E: Plant pathology. Deadly wheat fungus threatens world's breadbaskets. Science 2007, 315:1786-1787.

18. Heath MC: Light and electron microscope studies of the interactions of host and non-host plants with cowpea rust-Uromyces phaseoli var. vignae. Physiological Plant Pathology 1974, 4:403-408. IN401-IN404, 409-414.

19. Heath MC: Partial characterization of the electron-opaque deposits formed in the non-host plant, French bean, after cowpea rust infection. Physiological Plant Pathology 1979, 15:141-144. IN145-IN146, 145-148.

20. Heath MC: Resistance of plants to rust infection. Phytopathology 1981, 71:971-974.

21. Niks R: Comparative histology of partial resistance and the nonhost reaction to leaf rust pathogens in barley and wheat seedlings. Phytopathology 1983, 73:60-64.

22. Niks R: Haustorium formation by Puccinia hordei in leaves of hypersensitive, partially resistant, and nonhost plant genotypes. Phytopathology 1983, 73:64-66

23. Hoogkamp T, Chen WQ, Niks R: Specificity of prehaustorial resistance to Puccinia hordei and to two inappropriate rust fungi in barley. Phytopathology 1998, 88:856-861.

24. Shafiei R, Hang C, Kang JGU, Loake GJ: Identification of loci controlling non-host disease resistance in Arabidopsis against the leaf rust pathogen Puccinia triticina. Molecular Plant Pathology 2007, 8:773-784.

25. Azinheira HGAHG, Silva MCSMC, Talhinhas PTP, Medeira CMC, Maia IMI Anne-Sophie Petitot ASP, Fernandez DFD: Non-host resistance responses of Arabidopsis thaliana to the coffee leaf rust fungus (Hemileia vastatrix). Botany 2010, 88:621-629.

26. Zhang H, Wang C, Cheng Y, Wang X, Li F, Han Q, Xu J, Chen X, Huang L, Wei G: Histological and molecular studies of the non-host interaction between wheat and Uromyces fabae. Planta 2011, 234:979-991.

27. Prats E, Martinez F, Rojas-Molina M, Rubiales D: Differential effects of phenylalanine ammonia lyase, cinnamyl alcohol dehydrogenase, and energetic metabolism inhibition on resistance of appropriate host and nonhost cereal-rust interactions. Phytopathology 2007, 97:1578-1583.

28. Jafary H, Albertazzi G, Marcel TC, Niks RE: High diversity of genes for nonhost resistance of barley to heterologous rust fungi. Genetics 2008, 178:2327-2339

29. Ayliffe $M$, Devilla R, Mago R, White $R$, Talbot M, Pryor A, Leung $H$ : Nonhost resistance of rice to rust pathogens. Molecular Plant-Microbe Interactions 2011, 24:1143-1155.
30. Diego R: Faba beans in sustainable agriculture. Field Crops Research 2010, 115:201-202.

31. Bennett MD, Leitch IJ: Nuclear DNA amounts in angiosperms. Ann Bot 1995, 76:113-176.

32. Ellis J: Insights into nonhost disease resistance: Can they assist disease control in agriculture? The Plant Cell 2006, 18:523-528.

33. Huitema E, Vleeshouwers VGAA, Francis DM, Kamoun S: Active defence responses associated with non-host resistance of Arabidopsis thaliana to the oomycete pathogen Phytophthora infestans. Molecular Plant Pathology 2003, 4:487-500.

34. Perumalla C: Effect of callose inhibition on haustorium formation by the cowpea rust fungus in the non-host, bean plant. Physiol Mol Plant Pathol 1989, 35:375-382

35. Škalamera D, Jibodh S, Heath MC: Callose deposition during the interaction between cowpea (Vigna unguiculata) and the monokaryotic stage of the cowpea rust fungus (Uromyces vignae). New Phytol 1997, 136:511-524.

36. Prats E, Llamas MJ, Rubiales D: Characterization of resistance mechanisms to Erysiphe pisi in Medicago truncatula. Phytopathology 2007, 97:1049-1053.

37. Mittler R: Oxidative stress, antioxidants and stress tolerance. Trends Plant Sci 2002, 7:405-410.

38. Jacobs AK, Lipka V, Burton RA, Panstruga R, Strizhov N, Schulze-Lefert $P$, Fincher GB: An Arabidopsis callose synthase, GSL5, is required for wound and papillary callose formation. The Plant Cell 2003, 15:2503-2513.

39. Levine $A$, Tenhaken $\mathrm{R}$, Dixon $\mathrm{R}$, Lamb $\mathrm{C}: \mathrm{H}_{2} \mathrm{O}_{2}$ from the oxidative burst orchestrates the plant hypersensitive disease resistance response. Cell 1994, 79:583-593.

40. Osbourn AE: Preformed antimicrobial compounds and plant defense against fungal attack. The Plant Cell 1996, 8:1821-1831.

41. Van Loon L, Rep M, Pieterse C: Significance of inducible defenserelated proteins in infected plants. Annu Rev Phytopathol 2006, 44:135-162

42. Van Loon L, Van Strien E: The families of pathogenesis-related proteins, their activities, and comparative analysis of PR-1 type proteins. Physiol Mol Plant Pathol 1999, 55:85-97.

43. Schenk PM, Kazan K, Wilson I, Anderson JP, Richmond T, Somerville SC, Manners JM: Coordinated plant defense responses in Arabidopsis revealed by microarray analysis. Proc Natl Acad Sci 2000, 97:11655-11660.

44. Glazebrook J: Contrasting mechanisms of defense against biotrophic and necrotrophic pathogens. Annu Rev Phytopathol 2005, 43:205-227.

45. Mauch F, Mauch-Mani B, Boller T: Antifungal hydrolases in pea tissue: II. Inhibition of fungal growth by combinations of chitinase and $\beta-1$, 3-glucanase. Plant Physiol 1988, 88:936-942.

46. Edreva A: Pathogenesis-related proteins: research progress in the last 15 years. Plant Physiol 2005, 31:105-124

47. Park CJ, Kim KJ, Shin R, Park JM, Shin YC, Paek KH: Pathogenesis-related protein 10 isolated from hot pepper functions as a ribonuclease in an antiviral pathway. The Plant Journal 2004, 37:186-198.

48. Liu JJ, Ekramoddoullah AKM: The family 10 of plant pathogenesis-related proteins: Their structure, regulation, and function in response to biotic and abiotic stresses. Physiol Mol Plant Pathol 2006, 68:3-13.

49. Leon J, Lawton MA, Raskin I: Hydrogen peroxide stimulates salicylic acid biosynthesis in tobacco. Plant Physiol 1995, 108:1673-1678.

50. Devadas SK, Enyedi A, Raina R: The Arabidopsis hrl1 mutation reveals novel overlapping roles for salicylic acid, jasmonic acid and ethylene signalling in cell death and defence against pathogens. The Plant Journal 2002, 30:467-480.

51. Kuźniak $\mathrm{E}$, Urbanek $\mathrm{H}$ : The involvement of hydrogen peroxide in plant responses to stresses. Acta Physiologiae Plantarum 2000, 22:195-203.

52. Gutierrez N, Giménez MJ, Palomino C, Avila CM: Assessment of candidate reference genes for expression studies in Vicia faba L. by real-time quantitative PCR. Mol Breed 2010, 28:13-24.

53. Kang Z, Shang H, Li Z: Fluorescence staining technique of wheat rust tissue. Plant Protection 1993, 19:27 (in Chinese).

54. Thordal-Christensen $\mathrm{H}$, Zhang Z, Wei Y, Collinge DB: Subcellular localization of $\mathrm{H} 2 \mathrm{O} 2$ in plants. $\mathrm{H} 2 \mathrm{O} 2$ accumulation in papillae and hypersensitive response during the barley-powdery mildew interaction. The Plant Journal 1997, 11:1187-1194.

55. Wang CF, Huang LL, Buchenauer $\mathrm{H}$, Han QM, Zhang HC, Kang ZS: Histochemical studies on the accumulation of reactive oxygen species 
$\left(\mathrm{O}_{2}^{-}\right.$and $\left.\mathrm{H}_{2} \mathrm{O}_{2}\right)$ in the incompatible and compatible interaction of wheatPuccinia striiformis f, sp, tritici. Physiol Mol Plant Pathol 2007, 71:230-239.

56. Hood M, Shew H: Applications of $\mathrm{KOH}$-aniline blue fluorescence in the study of plant-fungal interactions. Phytopathology 1996, 86:704-708.

57. Livak KJ, Schmittgen TD: Analysis of relative gene expression data using real-time quantitative PCR and the 2-[Delta][Delta] CT method. Methods 2001, 25:402-408.

doi:10.1186/1471-2229-12-96

Cite this article as: Cheng et al:: Characterization of non-host resistance in broad bean to the wheat stripe rust pathogen. BMC Plant Biology 2012 12:96.

\section{Submit your next manuscript to BioMed Central and take full advantage of:}

- Convenient online submission

- Thorough peer review

- No space constraints or color figure charges

- Immediate publication on acceptance

- Inclusion in PubMed, CAS, Scopus and Google Scholar

- Research which is freely available for redistribution 